\title{
Prospective System Analysis of the Pre- and Early Hospital Care in Severe Head Injury in Bavaria at a Population-Based Level
}

\author{
A. Baethmann A. Wirth A. Schlesinger-Raab and Study Group of \\ BMBF Research Consortium Neurotraumatology and Neuropsychological \\ Rehabilitation ${ }^{1}$ \\ Institute for Surgical Research, Klinikum of University of Munich, Germany
}

\section{Key Words}

Traumatic brain injury - Pre- and early clinical patient management $\cdot$ System analysis

\section{Introduction}

Traumatic injuries leading to severe brain damage constitute the most frequent causes of morbidity and mortality up to an age of 45 years, not only in the industrialized western world but probably more so in less developed countries. Severe head injury is the most important sequelae of trauma, dominating the outcome of afflicted victims, and particularly affecting the male population of the younger generation. The socio-economic burden is enormous aside from personal suffering and losses. Sequelae not only involve lost expenses for education and professional training but also the lost future income and

J. Assal, S. Aydemir, M. Bayeff-Filloff, J Beck, A. Belg, A. Boscher, D. Chapuis, H.-G. Dietz, J. Döffinger, W. Eisenmenger, W. Gerstner, W.-E. Göbel, P. Große, T. Grumme, L. Gutermuth, D. Hölzel, F. Höpner, R. Huf, H. Jaksche, U. Jensen, M. Kettemann, R. Ketterl, U. Kirmayer, D. Kolodziejcyk, W. Köstler, J. Kuznik, C. Lackner, G. Lenz, H. Lochbihler, C. Lumenta, S. Martin, A. Preisz, G. Prokscha, G. Regel, H. Reischl, H.-J. Reulen, F. Rothmeier, D. Sackerer, S. Schneck, L. Schweiberer, F. Sommer, H.-J. Steiger, E. Stolpe, W. Stummer, P. Tanner, A. Trappe, J. v. Twickel, P. Ueblacker, W. Wambach, P. Wengert, S. Zimmerer.

\begin{tabular}{ll}
\hline KARGER & ( ) 2002 S. Karger AG, Basel \\
0014-312X/02/0342-0042\$18.50/0 \\
$\begin{array}{l}\text { Fax +4161306 1234 } \\
\begin{array}{l}\text { E-Mail karger@karger.ch } \\
\text { www.karger.com }\end{array}\end{array}$ & $\begin{array}{l}\text { Accessible online at: } \\
\text { www.karger.com/journals/esr }\end{array}$
\end{tabular}

expenses raised by the continuous, sometimes lifelong care in the case of severe disability.

In Germany, approximately 280,000 patients are annually admitted to hospitals with the diagnosis of brain injury, fortunately enough mostly of mild or moderate nature only. This notwithstanding ca. $5 \%$ of cases can be considered as severe according to the worldwide accepted definition of a neurological deficit of $\leq 8$ points of the Glasgow Coma Score for 6-24 h after trauma, or deterioration to that level within $24 \mathrm{~h}$. Based on the Federal Bureau of Statistics, Wiesbaden, Germany, 7,705 patients were dying in 1999 from severe head injury in the Federal Republic of Germany (ICD 10 diagnosis: (a) intracranial injuries, (b) skull fracture), which may translate into a frequency of severe traumatic brain injury per year of 12,630 [1]. From this figure, an incidence of 1,200 patients with severe disabilities per annum can be extrapolated, which yearly is increasing the prevalence of severely disabled already surviving as dependents in specific care facilities or at home.

The treatment of patients with traumatic brain injury encompasses a comprehensive package of measures, not only consisting of the preclinical resuscitation and management, but also of the early clinical diagnostic procedures and treatment with all its logistical and organizational support. Their effective administration requires great competence and skills, among others of the emergency physicians and preclinical rescue personnel at the

Prof. A. Baethmann

Institute for Surgical Research, Klinikum of University of Munich

D-81366 Munich (Germany)

Tel +49897095 4350/1, Fax +498970954353

E-Mail baethman@icf.med.uni-muenchen.de 
scene, but also of the services providing clinical care. Further, a high level of organization and logistics of the preclinical rescue is necessary together with a dense availability of trauma centers with neurosurgical competence including intensive care facilities. Last but not least, head injury patients require sophisticated neuropsychological rehabilitation - a formidable challenge.

Specific pharmacological agents affording neuroprotection to prevent the development of secondary brain damage have not been found so far to be effective in prospective clinical trials, notwithstanding that a variety of methods have a remarkable therapeutical potential under experimental conditions. The problem of why these agents and procedures, e.g. interfering with neuroexcitotoxic glutamate effects, formation of $\mathrm{O}_{2}$-derived free radicals, and other mechanisms causing secondary brain damage (i.e. an additional loss of brain parenchyma) has been extensively analysed [2]. It is hoped that conclusions and suggestions emerging from this and former metaanalyses eventually lead to solutions out of the present deadlock, providing novel design and concepts for future trials to more convincingly elucidate whether experimentally efficient methods of neuroprotection are useful for the treatment of severe head injury patients. Until then, the currently available treatment and management armamentarium should continuously be subjected to a critical analysis as to its efficacy and remaining deficits.

This, actually is the purpose of an elaborate System Analysis of the BMBF Research Consortium Neurotraumatology and Neuropsychological Rehabilitation supported by the Federal Ministry of Education and Research in Germany [3]. Details of this analysis include documentation of the course of events, so to say from the time point of an accident together with the patients' state, e.g. level of consciousness, visible injuries, complications, as arterial hypotension or hypoxia from aspiration, etc. In addition, rescue measures at the scene, as intubation, infusions, and others were protocolled. The present investigations were carried out on a population-based level, representing a catchment area in Southern Bavaria of ca. 5.6 Mio. inhabitants to collect epidemiologically valid data also with regard to the incidence of severe head injury and its outcome.

In the course of these investigations it became obvious that outcome findings published in the past quite often are influenced by the purpose of a given study, consequently the in- and exclusion criteria adjusted to the specific objectives of a given trial. With such a procedure a major number of patients may be eliminated and ignored, often those who are dying within $24 \mathrm{~h}$ after the traumatic insult. Another point of the present investigation was to assess the frequency of severe head injury cases, dying prior to hospital admission for which practically no information is made available by former investigations. Reliable data are missing also on the frequency of the severely disabled survivors, which often constitute a group of young male victims remaining dependent for the rest of their life in rehabilitation facilities or at home. Quantitative information on the annual incidence of this outcome, however, is important for the planning of necessary institutional capacities and, thereby, of interest for insurance organizations.

With regard to the assessment of the present management quality, a major point was to gather information on the time-course of care with onset at the scene of an accident until arrival of the emergency squad, intubation and stabilization of the patient, as e.g. recognizable from normalisation of the blood pressure, and others. Further, the time point of hospital admission was of interest, the subsequent establishment of the CT diagnosis, and - last but not least - conclusion of acute care, as defined by the beginning of a neurosurgical operation or transfer to the intensive care unit. An important objective was also concerned with the remaining significance of secondary brain damage for the outcome of patients with severe head injury.

As known, the prognosis in traumatic brain injury is largely determined by two factors: (a) nature and severity of the primary lesion of the brain produced at the moment of an insult and (b) the subsequent sequelae resulting in secondary damage of the brain - the additional loss of brain parenchyma. The distinction is not of academic interest but clinically highly significant, as only the complications leading to secondary brain damage might be influenced by the management and treatment. This explains, why a better understanding of underlying mechanisms is so important, since a further reduction of the morbidity and mortality in severe head injury can only be expected from their more efficient prevention and treatment. This not only demonstrates the great significance of progress in the patient management and care at all levels, beginning at the scene of an accident to more effectively inhibit the development of avoidable complications, but also of the availability of neuroprotective measures and agents proving effective in clinical trials.

In this context, it is quite clear that a severely headinjured patient is at high risk, not only during the preclinical rescue period with usually less than optimal conditions of resuscitation and stabilization, but also during the early clinical phase as indicated by the fact that the mortality 
peak occurs at the first/second day after trauma. Whereas it is easily understood that a multitude of complications, as aspiration, internal bleeding causing cardiovascular failure and other instabilities are liable to put the patient at risk during the prehospital rescue period, problems remain after the patient has been admitted to the hospital. Studies of avoidable complications in children succumbing from head injury in England have shown that dangerous events are taking place during the clinical care period approximately 2-3 times more frequently than during the preclinical rescue [4]. A prospective risk assessment was made under the coordination of the late J.D. Miller, Univ. Edinburgh/Scotland in severe head-injured patients. Important physiological parameters, as intracranial pressure, blood pressure, blood gases and others were densely monitored during an intra-hospital transfer of patients, from the intensive care unit to CT scanning, among others. Accordingly, in no less than $83 \%$ of these manoeuvres the patients' homeostasis was severely impaired as concluded, for example, from an increase of the intracranial pressure and arterial blood pressure, or a decrease of the systemic blood pressure together with arterial hypoxia [5]. This demonstrates that even under well controlled stable conditions in a maximal care hospital, complications being avoidable or not - evolve which may support the development of secondary brain damage.

\section{Study Objectives}

In view of the above considerations an in-depth analysis of the major components of the management and treatment of patients with head injury, beginning at the scene as soon as possible after a traumatic insult, and including the early clinical care phase appeared to be mandatory. For that purpose, a Study Group was established and coordinated by the University of Munich with support by the BMBF Research Consortium Neurotraumatology and Neuropsychological Rehabilitation. Its mission was to systematically document and collect pertinent data to assess the efficacy of the present care system (i.e. management, logistics, organization, etc.). The analysis was carried out in collaboration with more than 30 hospitals in Munich and the other larger cities in the catchment area and organizations, as the Red Cross, emergency services including the dispatch centers for rescue vehicles and helicopters, fire brigades, and - last but not least - the Department of Forensic Medicine, the Institute for Surgical Research, and Institute for Biometrics and Epidemiology of the University of Munich.
For the population based investigations patients were recruited, if they were matching the following inclusion criteria: neurological deficit of $\leq 8$ points of the Glasgow Coma Scale at the site of an accident or deterioration to that level within $48 \mathrm{~h}$. With regard to the geographical definition of the catchment area, patients suffering an insult within this area, but receiving treatment outside or, vice versa, were excluded, as well as those without pathology in the CT scan, and finally children younger than two years. The Study Apparatus was organized as a network of the ten dispatch centers in the catchment area, including four helicopter stations in Munich, Ingolstadt, Kempten, Traunstein, and forensic medical institutions in Munich, Kempten, Memmingen, Ingolstadt and Augsburg.

Most important, documentation assistants (young physicians at the beginning of their medical training) were hired and strategically distributed within the catchment area, i.e. in Munich, Augsburg, Ingolstadt, Murnau, Traunstein, Vogtareuth and Altötting. Each colleague was establishing a close communication network with approximately 5-10 regional hospitals by daily telephone interviews and frequent site visits from where newly admitted patients with head injury were reported. Thereby, a close follow-up of the patients' course was afforded during the acute documentation period of the first 12 days after the accident.

The documentation network was coordinated by the Study Center localized at the Institute for Surgical Research of the Klinikum of the University of MunichGroßhadern. All relevant data and information was collected in a data bank. The Study Center was coordinated by biostatisticians, who not only were devising the software for the data bank and subsequent statistical analysis, but also carrying out a daily back-up of the data flow, utilizing advanced biometrical procedures including for the assessment of risk factors for the outcome.

Of all patients finally recruited for clinical documentation, the majority were seen at the site of an accident and transported by a ground-based ambulance provided with an emergency physician. One third of all patients admitted to hospitals received emergency treatment at the scene by a helicopter rescue staff also including an emergency physician. The most frequent mechanism of injury were jumps and falls of victims $>55$ years old, followed by traffic accidents involving cars, pedestrians, bicycle and motorcycle riders. In the group of cases dying at the scene prior to hospitalization, suicidal railway accidents and gun shot wounds were representing the most frequent causes of injury, followed by traffic accidents, jumps and falls. 
Arrival of the rescue squad with a physician at the scene was accomplished in the majority of cases within the legally required period after alarm. Rescue and resuscitation for stabilization of the patient was carried out according to the 'stay and play' philosophy. All the potentially outcome-relevant time periods, e.g. until intubation of patients, admission to the hospital, establishment of the CT diagnosis, or conclusion of acute care were documented in order to evaluate and assess the time-course of the preclinical and early clinical management. Conclusion of acute care was identified as the time point, when the patient was delivered to the intensive care unit or to the operation theatre for surgery. As reference, the time of the first alarm of the dispatch center in a given case from the scene of an accident was taken, since the time of an accident proper almost always is unavailable. In the current study, about $20 \%$ of patients were secondarily admitted to the final care hospital providing neurosurgery from a primary general trauma hospital. This was extending the period of acute care by approximately $100 \%$, a potentially important delay which was analysed as to its impact on the final outcome.

During the preclinical rescue phase important complications were documented, as respiratory distress, apnea, tracheal aspiration, tachy- or bradycardia, occurrence, severity, and duration of arterial hypotension (systolic blood pressure $<80 \mathrm{~mm} \mathrm{Hg}$ ). The latter is a major risk factor of poor outcome in severe head injury [6]. In addition, all pertinent measures of the preclinical management were protocolled, such as infusion of fluid, intubation, and ventilation with additional oxygen, analgo-sedation, and others. In this context, tracheal clearing, cardiac massage, defibrillation, or thoracic draining may be mentioned in addition. In patients with additional polytrauma with a higher risk of arterial hypotension, the effectivity of normalising arterial blood pressure was documented by repeated measurements of the systemic blood pressure at the scene immediately upon arrival of the emergency squad and continued until admission to the hospital.

The outcome of the hospitalised patients was studied at 3,6 , or 12 months after the accident. The prognosis of severe head injury was assessed with and without the cases dying prior to hospital admission. Analysis of the outcome by inclusion of the prehospital mortality is reflecting more appropriately the overall fatality from severe head injury as compared to many clinical analyses reported in the literature. Quite often, these are limited to the outcome of hospitalised patients sometimes even under exclusion of those dying within $24 \mathrm{~h}$ after trauma for a stratification of the patient population in drug trials. With inclusion of the prehospital fatalities the overall mortality was approaching a level $>60 \%$ with a correspondingly low fraction of cases with good outcome categories.

In conclusion, documentation of the course of patients with severe head injury was carried out for analysis of the management, care, and organization, beginning at the scene of an accident and continuing with a dense protocol during the first 12 days at the hospital. Outcome of the patients was assessed by using the Glasgow-OutcomeScale [7] at 3, 6, and 12 months. Such an analysis has to the best of our knowledge not been performed so far on a prospective basis with documentation of the patients course utilizing a dense network for data gathering. By this approach it is expected that novel information is provided on the persisting role of secondary brain damage for the outcome in severe head injury, and the remaining significance of avoidable complications. Since patients dying prior to hospitalisation were subjected to autopsy at a high frequency, the contribution of severe head injury to the prehospital mortality for the first time could also be reliably analysed. The findings from the current analysis, particularly the assessment of prevailing risk factors provide a solid basis for considerations concerning potentially necessary improvements of the organization and management. A management at its best possible level, however, is a major requirement for the successful conduct of clinical trials on novel neuroprotective agents, as the patient outcome must not be influenced by avoidable complications leading to secondary brain damage.

\section{Acknowledgement}

The secretarial assistance for preparation of the manuscript by Helga Kleylein and Pia Handke is gratefully acknowledged.

This report is based on a publication for the Proceedings of the VII. International Symposium 'Mechanisms of Secondary Brain Damage from Trauma and Ischemia', Acta Neurochirurgica, Vienna 2002 , in press [8].

Eur Surg Res 2002;34:42-46 


\section{References}

1 Sterbefälle 1999 nach ausgewählten Todesursachen, Altersgruppen und Geschlecht. Statistisches Bundesamt Wiesbaden, 1999, Fachserie 12, Reihe 4.

2 Maas AIR, Steyerberg EW, Murray GD., Bullock R, Baethmann A, Marshall LF, Teasdale GM: Why have recent trials of neuroprotective agents in head injury failed to show convincing efficacy? A pragmatic analysis and theoretical considerations. Neurosurgery 1999;44:12861298.

3 Lehr D, Baethmann A, and Study Group: Reulen H-J, Steiger H-J, Lackner Ch, Stummer W, Wirth A, Hölzel D, Stolpe E, Assal J, Belg A, Schrödel M, Müller N, Ueblacker P, Chlistalla A, Schneider G, Schweiberer L, Dietz H-G, Trappe A, Göbel W-E, Jaksche H, Messner V, Grumme Th, Wenger P, Müller H, Döffinger J, Lumenta Ch, Gerstner W, Prokscha G, Sackerer D, Höfner F, Eisenstein T, Lenz G, Preisz A, Rothmeier F, Kirmayer U, Böhme M, Horak W, and Weess Th: Management of patients with severe head injury in the preclinical phase: A prospective analysis. J Trauma: Injury, Infection, Critical Care 1997;42:S71-S75.
4 Sharples PM, Storey A, Aynsley-Green A, Eyre JA: Avoidable factors contributing to death of children with head injury. Brit Med J 1990; 300:87-91.

5 Andrews PJD, Piper IR, Dearden NM, Miller JD: Secondary insults during intrahospital transport of head injured patients. Lancet 1990;335:327-330.

6 Marmarou A, Anderson RL, Ward JD, Choi SC, Young HF, Eisenberg HM, Foulkes MA, Marshall LF, Jane JA: Impact of ICP-instability and hypotension and outcome in patients with severe head trauma. J Neurosurg 1991;75: S59-S66.

7 Jennett B, Bond M: Assessment of outcome after severe brain damage: A practical scale. Lancet 1975;1:480-484.
8 Wirth A, Baethmann A, Schlesinger-Raab A, and Study Group of BMBF-Research Consortium Neurotraumatology and Neuropsychological Rehabilitation: Assal J, Aydemir S, BayeffFilloff M, Beck J, Belg A, Boscher A, Chapuis D, Dietz H-G, Döffinger J, Eisenmenger W, Gerstner W, Göbel W-E, Große P, Grumme Th, Gutermuth L, Hölzel D, Höpner F, Huf R, Jaksche H, Jensen U, Kettemann M, Ketterl R, Kirmayer U, Kolodziejcyk D, Köstler W, Kuznik J, Lackner Ch, Lenz $G$, Lochbihler $H$ Lumenta Ch, Martin S, Preisz A, Prokscha G, Regel G, Reischl H, Reulen H-J, Rothmeier F, Sackerer D, Schneck S, Schweiberer L, Sommer F, Steiger H-J, Stolpe E, Stummer W, Tanner P, Trappe A, v. Twickel J, Ueblacker P, Wambach W, Wengert P, Zimmerer S: Prospective documentation and analysis of severe head injury patients during the pre- and early hospital care at a population based level. Acta Neurochir, Suppl 2002, in press. 